\title{
Antibody Detection, Isolation, Genotyping, and Virulence of Toxoplasma gondii in Captive Felids from China
}

\author{
Yu-Rong Yang ${ }^{1 *}$, Yong-Jie Feng ${ }^{1}$, Yao-Yao Lu ${ }^{1}$, Hui Dong ${ }^{1}$, Tong-Yi Li ${ }^{2}$, Yi-Bao Jiang ${ }^{1}$, \\ Xing-Quan Zhu ${ }^{3}$ and Long-Xian Zhang ${ }^{1}$ \\ ${ }^{1}$ Department of Basic Veterinary, College of Animal Science and Veterinary Medicine, Henan Agricultural University, \\ Zhengzhou, China, ${ }^{2}$ Zhengzhou Zoo, Zhengzhou, China, ${ }^{3}$ State Key Laboratory of Veterinary Etiological Biology, Key \\ Laboratory of Veterinary Parasitology of Gansu Province, Lanzhou Veterinary Research Institute, Chinese Academy of \\ Agricultural Sciences, Lanzhou, China
}

OPEN ACCESS

Edited by:

Paul J. Brindley,

George Washington University,

United States

Reviewed by:

Xichen Zhang,

College of Veterinary Medicine,

Philippines

Houqiang Luo,

Wenzhou Vocational College of

Science and Technology, China

*Correspondence:

Yu-Rong Yang

yangyu7712@sina.com

Specialty section:

This article was submitted to

Infectious Diseases,

a section of the journal

Frontiers in Microbiology

Received: 03 March 2017

Accepted: 11 July 2017

Published: 25 July 2017

Citation:

Yang $Y$-R, Feng $Y$-J, Lu Y-Y, Dong $H$

Li T-Y, Jiang $Y-B$, Zhu X-Q and Zhang L-X (2017) Antibody Detection, Isolation, Genotyping, and Virulence of

Toxoplasma gondii in Captive Felids from China. Front. Microbiol. 8:1414.

doi: 10.3389/fmicb.2017.01414
The felids are the only definitive hosts of Toxoplasma gondii, which could excrete oocysts into the environment and provide an infection source for toxoplasmosis in various warm-blooded animal species, particularly the captive felids that live close to human communities. The infection rate of the captive felids is a perfect standard in detecting the presence of Toxoplasma gondii oocysts in the environment. In this study, sera or tissue samples from zoo (1 young tiger, 2 adult tigers, 6 young lions), farm (10 masked palm civets), and pet hospital (28 cats) from Henan Province (China) were collected. The sera $(n=47)$ were tested for immunoglobulin $\mathrm{G}(\mathrm{lgG})$ antibodies against $T$. gondii by using modified agglutination test (MAT), whereas the hearts tissue $(n=40)$ were bioassayed in mice to isolate $T$. gondii strains. The genotype was distinguished by using PCR-RFLP of 10 loci (SAG1, SAG2, SAG3, GRA6, BTUB, L358, c22-8, PK1, c29-2, and Apico). The detection rate for the T. gondii antibody in captive felids was $21.3 \%$ (10/47). One viable T. gondii strain ( $\mathrm{TgCatCHn} 4)$ was obtained from a cat heart tissue, and its genotype was ToxoDB\#9. The oocysts of ToxoDB\#9 were collected from a T. gondii-free cat. The virulence of TgCatCHn4 was low and no cysts were detected in the brain of mice at 60 days post-inoculation. The finding of the present study suggested a widespread exposure of $T$. gondii for felids in Henan Province of central China, particularly those from the zoological gardens and homes. ToxoDB\#9 was the predominant strain in China. Preventive measures against $T$. gondii oocyst contamination of various components of the environment should thus be implemented, including providing pre-frozen meat, well-cooked cat food, cleaned fruits and vegetables, monitoring birds and rodents, inactive T. gondii oocysts in felids feces, and proper hygiene.

Keywords: Toxoplasma gondii, captive felids, public health, epidemiology, isolation, genotype, virulence, oocysts

\section{INTRODUCTION}

Toxoplasma gondii infects warm-blooded animals, including birds, livestock, humans, and felids. T. gondii induces lymphadenopathy, retinochoroiditis, encephalitis, abortion, and death in immunocompromised individuals (Hide, 2016). Felids are important in the epidemiology of toxoplasmosis for these are the only definitive hosts that can shed environmentally resistant oocysts 
(Dubey, 2010). One T. gondii free domestic or wild felid could shed millions of oocysts after ingestion raw meat that contain T. gondii cyst, and the oocysts could survive in soil for years. Furthermore, oocysts are transported via freshwater runoff into the ocean and thus may be a threat to the marine ecosystem, particularly marine mammals (Vanwormer et al., 2016). Approximately $16 \%$ of beach cast carcasses of sea otters in California was due to T. gondii (Miller et al., 2004).

There are 37 species of felids around the world, with China hosting at least 20 species, with most of these endangered (Johnson et al., 2006), and an estimated 53 millions are domestic cats. The number of wild felids in China has declined due to the destruction of natural habitats in the advent of agricultural development and economic expansion. Most existing felids are artificially bred in farms or kept in zoological parks.

The seroprevalence of $T$. gondii in felids from zoo $(84.2 \%)$ (Zhang et al., 2000) and masked palm civets (27.6\%) from a farm (Hou et al., 2016) was evaluated by using a modified agglutination test (MAT). The prevalence of toxoplasmosis was about $50 \%$ in cats from China, and viable T. gondii strains had been isolated from tissues or fecal samples of domestic cats (Dubey et al., 2007; Zhou et al., 2009; Chen et al., 2011; Qian et al., 2012; Wang et al., 2013; Li et al., 2015; Yang et al., 2015). The epidemiological role of felids in toxoplasmosis still needs to be fully established. Accordingly, the present study aimed to determine the frequency of T. gondii antibodies in felids from zoos, farms, and pet hospitals, in an attempt to isolate viable T. gondii.

\section{MATERIALS AND METHODS}

\section{Sample Collection}

From 2015 to 2017, the sick or dead felids due to idiopathic reasons were gathered from zoos, farms, and pet hospitals in Henan Province $\left(33^{\circ} \mathrm{N}, 113.30^{\circ} \mathrm{E}\right)$, which is located in central China and has a humid and subtropical climate. Tissue or serum samples were collected from these animals, placed in a cooler box, and then transported to the Laboratory of Veterinary Pathology of Henan Agricultural University (Zhengzhou, Henan Province, China) for pathological diagnosis (Table 1, Figure 1). A total of 21 batches were obtained, including 28 pet cats (Felis catus) (28 hearts, 28 sera), 10 masked palm civets (Paguma larvata) (7 hearts, 10 sera), 3 tigers (Panthera tigris altaica) ( 2 hearts, 3 sera), and 6 lions (Panthera leo) (3 hearts, 6 sera). Feline tissue and serum samples were stored at $4^{\circ} \mathrm{C}$ and tested within 1 week. Most pet cats were fed commercial cat food. The masked palm civets were fed cooked chicken giblets and cleaned fruit and vegetables in the farm. Tigers and lions were fed raw chicken and pork ribs in the zoo.

\section{Serological Examination by MAT}

Forty-seven serum samples from captive felids were serologically assessed for antibodies against $T$. gondii by using MAT at a dilution of 1:25 to the final maximum titer (Dubey and Desmonts, 1987). The positive and negative controls, and the

Abbreviations: MAT, modified agglutination test; DPI, day post-inoculation; PCR, polymerase chain reaction. blank were included in each microtiter plate. Whole formalin fixed T. gondii tachyzoites was kindly provided by Dr. J. P. Dubey (ARS, USDA), which was obtained from Kerafast company (Catalog No. EH2002).

\section{Isolation of Viable T. gondii from Felid Hearts by Using a Bioassay in Mice}

Specific-pathogen-free Swiss mice were supplied by the Zhengzhou University Laboratory Animal Center (China), mouse grant No. was 41003100000236 . The hearts of captive felids $(n=40)$ were weighed, washed, homogenized, digested in pepsin, centrifuged, and neutralized, and the homogenate was inoculated subcutaneously into five outbred Swiss mice (healthy, weight $\geq 25 \mathrm{~g}$, ages $\geq 8$ weeks) following the description by Dubey (2010) and Yang et al. (2017). Pepsin was purchase from Sigma (Product No. P7012). The seronegative (MAT titer < 25) tissues in each batch were pooled prior to digestion, whereas the seropositive tissues (MAT titer $\geq 25$ ) were digested and bioassayed individually. The tachyzoites or tissue cysts of $T$. gondii were examined in tissue imprints of lungs and brains of mice. The surviving mice were bled on day 60 post-inoculation (DPI), and the T. gondii serum antibodies were tested by using MAT with 1:25 and 1:200 dilutions. The mice were sacrificed at $61 \mathrm{DPI}$, and squash of their brains were prepared and examined for tissue cysts. All brains of the mice were homogenized and sub-passaged into new groups of mice subcutaneously. The mice were determined to be infectived with $T$. gondii when tachyzoites or tissue cysts were detected or showed seropositive MAT results.

\section{T. gondii Oocyst Collection and Virulence Evaluation}

Toxoplasma gondii-free cats were fed tissues of $T$. gondiipositive Swiss mice that were inoculated with infected feline derived homogenates. Their feces were collected daily for 3 weeks and stored at $4{ }^{\circ} \mathrm{C}$ to prevent oocyst sporulation. The oocysts were collected from the feces as previously reported (Dubey, 2010). Briefly, fecal samples were washed in water, gauze filtered, and then floated in $33 \%$ sucrose solution. The supernatant was then collected and kept in $2 \%$ sulfuric acid in $25^{\circ} \mathrm{C}$ for sporulation. Virulence of the T. gondii isolated from the felid was evaluated in Swiss mice. Sporulated oocysts were neutralized, counted in a disposable hemocytometer, and diluted 10 -fold from $10^{-1}$ to $10^{-7}$ to reach an end-point of $<1$ oocyst. Then, $<1,10^{0}, 10^{1}, 10^{2}, 10^{3}, 10^{4}$, and $10^{5}$ oocysts were orally administered to five Swiss mice for each dilution. The clinical symptoms and mortality were recorded daily, and 60 days later, all surviving mice were bled and tested for IgG antibodies to T. gondii by the MAT using titers between 1:25 and 1:200. The mice were sacrificed at $61 \mathrm{DPI}$, and all the tissues were fixed in $10 \%(\mathrm{v} / \mathrm{v})$ neutral buffered formalin. The tissues were processed by using routine histological processing techniques, and embedded in paraffin. Paraffin sections (5 $\mu \mathrm{m}$ in thickness) of the samples were prepared and stained with hematoxylin and eosin (H\&E) and immunohistochemistry (IHC). The primary antibody was rabbit anti-T. gondii polyclonal antibody, and tissue sections of a ToxoDB\#216 T. gondii-infected model was used as 


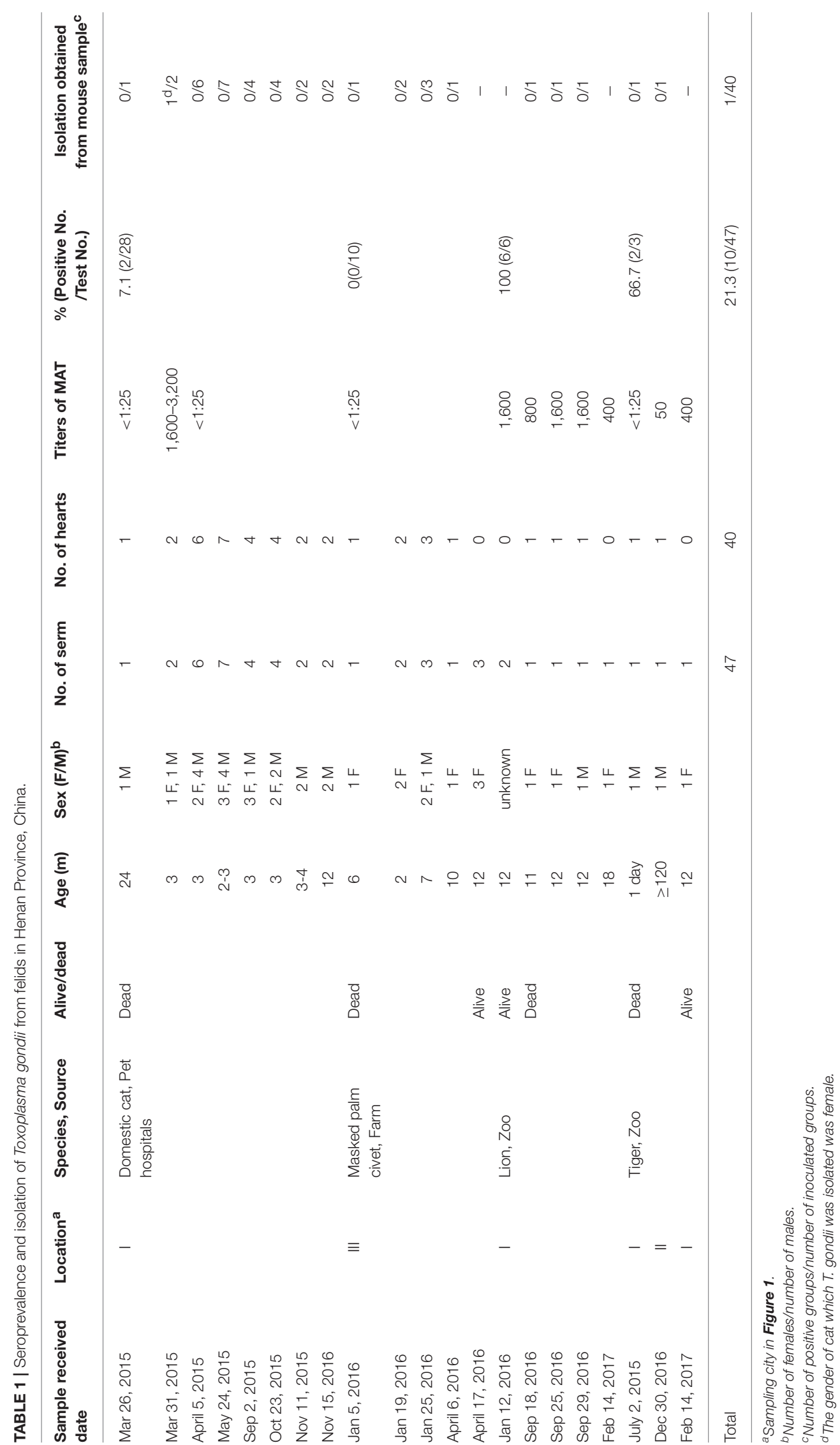



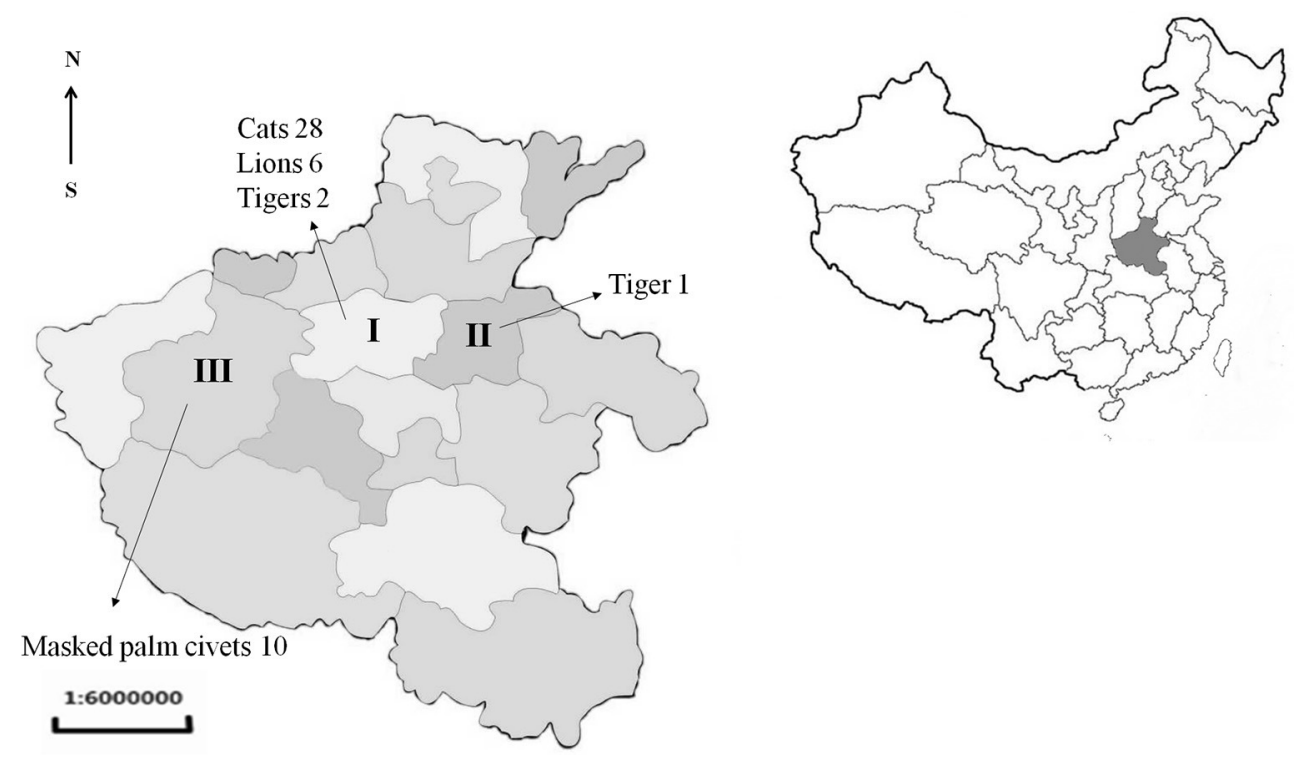

FIGURE 1 | Location and number of samples received from Henan province of China. I, Zhengzhou; II, Kaifeng; III, Luoyang.

positive control (kindly provided by Dr. Dubey, ARS, USDA). A mouse-specific HRP/DAB IHC detection kit was purchased from Abcam (ab64264). All mice were considered infected when antibodies of $T$. gondii or parasites were detected in their sera or tissues.

\section{Cell Cultivation and Genotyping}

Tissue (brain, heart, and tongue) homogenates of $T$. gondiipositive mice were seeded into Vero cell cultures (RPMI 1640, $10 \%$ fetal bovine serum, $37^{\circ} \mathrm{C}, 5 \% \mathrm{CO}_{2}$ ), refresh the culture fluid after $1 \mathrm{~h}$ then the cell culture fluid was replaced twice a week (Dubey, 2010). The number of cysts in the brains of the mice was counted under a microscope using the method described by Dubey et al. (2012). DNA was extracted from T. gondii oocysts which were shed by cat. A commercial DNA extraction kit (Tiangen Biotec Company, DP304) was used in DNA extraction. T. gondii genotype was distinguished by PCR-RFLP of 10 genetic markers (SAG1, SAG2, SAG3, GRA6, BTUB, L358, PK1, c22-8, c29-2, and Apico) (Su et al., 2010). References of T. gondii DNA was included in all batches.

\section{Ethics Approval}

The study was approved by the Institutional Animal Use Protocol Committee of the Henan Agricultural University, China. The Beijing Association for Science and Technology (Approval SYXK [Beijing] 2007-0023) approved the protocol used in this study. All captive felids and mice were handled in strict accordance with the good animal practices of the Animal Ethics Procedures and Guidelines of the People's Republic of China.

\section{Statistical Analysis}

Statistical analysis was performed by using Graph Pad Prism 7.0 software, which was developed by GraphPad Software Inc.,
San Diego, CA, USA. The chi-square test or Fisher's exact test was used in data analysis. $P<0.05$ was considered statistically significant.

\section{RESULTS}

Modified agglutination test (MAT) analysis indicated that the seropositive rate of IgG antibodies to T. gondii was $21.3 \%(10 / 47)$ in captive felids, $7.1 \%(2 / 28)$ in domestic cats, $0 \%(0 / 10)$ in masked civets, $66.7 \%(2 / 3)$ in tigers, and $100 \%(6 / 6)$ in lions. The titer of T. gondii in seropositive felids was high $(50-3,200)$ (Table 1). Seropositivity rates varied with respect to the source of the felids. The seroprevalence of T. gondii in felids from zoos $(88.9 \%, 8 / 9)$ was significantly higher than those from domestic felids $(7.1 \%, 2 / 28)$ and farms $(0 \%, 0 / 10)(P<0.01)$. In the present study, $6.9 \%(2 / 29)$ of felids $\leq 6$ months old were seropositive for $T$. gondii, whereas $44.4 \%(8 / 18)$ of those $>6$ months old were seropositive. The positive rate of $T$. gondii in adult felids was significantly higher compared to that in juveniles $(P=$ $0.0037)$. Female felids $(20.8 \%, 5 / 24)$ were more susceptible to $T$. gondii than males $(14.3 \%, 3 / 21)$, although this difference was not significant (Table 2).

A total of 40 felids heart homogenates were individually bioassayed in mice. All mice inoculated with animal tissues remained alive at 60 DPI. T. gondii antibodies were only detected in one group of mice at 60 DPI. Viable T. gondii were isolated from this positive group (Table 1). The tissues of $T$. gondiipositive mice were sub-inoculated into mice, fed to $T$. gondiifree cat, and seeded onto cell cultures for the propagation of parasites. This isolate T. gondii strain was successfully propagated in mice, and $T$. gondii occysts were detected in the feces of cat (Figure 2A); however, it showed a relatively low growth rate in cell culture during 6 month observation. The present study 
TABLE 2 | Effect of age, sex, and sample sources of felids on Toxoplasma gondiipositive rates.

\begin{tabular}{llccc}
\hline Factor & $\begin{array}{l}\text { Sample } \\
\text { type }\end{array}$ & $\begin{array}{l}\text { Sample } \\
\text { number }\end{array}$ & $\begin{array}{c}\text { Number of positive } \\
\text { samples and rate (\%) }\end{array}$ & P-value \\
\hline Age $^{*}$ & $\leq 6$ month & 29 & $2(6.9)$ & \\
& $>6$ month & 18 & $8(44.4)$ & 0.0037 \\
Sex & Female & 24 & $5(20.8)$ & \\
& Male & 21 & $3(14.3)$ & 0.7050 \\
Sample sources $^{*}$ & Farm & 10 & $0(-)$ & 1.000 \\
& Pet hospitals & 28 & $2(7.1)$ & \\
& Zoo & 9 & $8(88.9)$ & 0.0001
\end{tabular}

${ }^{\star} P$-value $<0.05$ by two-tailed chi-square tests for $T$. gondii in both age and sample sources groups.

was not successful in isolating T. gondii from tigers, lions, MAT seronegative masked palm civets, and cats.

Oocysts of the T. gondii strain TgcatHn4 were collected from the feces of $T$. gondii-free cat at days 6-11 after feeding it with mouse tissues. DNA was isolated from T. gondii oocysts. Genotype indicated that the isolate from the cat heart was of the ToxoDB genotype \#9. The mice were asymptomatic, no deaths were observed, and above $10^{3}$ oocysts induced $T$. gondii infection in all of the mice. The survival time post-inoculation with TgcatHn4 oocysts was $\geq 60$ days (Table 3). T. gondii cysts were not detected in brain smear or histologic section at 60 DPI, but observed at 138 DPI (Figure 2B). Compared to the virulent $T$. gondii strain (Figure 2D), the pathological lesions and parasites loading of the TgcatHn4 strain of T. gondii in the ileum of mice were not found at 60 DPI (Figure 2C).

\section{DISCUSSION}

The present study that aimed to assess the impact of $T$. gondii on captive felids faced several challenges. The first one was that the technique in handling large cats has not been well developed. The second was the limited number of serum and tissue samples. From 2015 to 2017, sick or dead felids were sent to our laboratory for etiological diagnosis, also allowed us to conduct surveys and perform specific research studies on T. gondii. This epidemiological study may provide clues on the process of $T$. gondii infection in felids.

In the present study, the prevalence of antibodies to $T$. gondii in felids from the zoo was higher than those from farm and pet hospital (Table 1). This difference may be related to the dietary habits or environment factors. Our survey indicated that the tigers and lions in zoos were generally fed with raw meat, most of the pet cats were given commercial cat food, and the masked palm civets in farm consumed cooked food. The possibility that raw meat contained infective $T$. gondii cysts was higher than that in well cooked meat. Raw meat could thus be a significant risk factor in felids from zoos, and considering that cooked meat is not suitable for them, then the use of pre-frozen meat may be an effective preventive measure against $T$. gondii infection. Furthermore, additional attention should be given to birds and rodents in the zoo as these may serve as intermediate hosts and mechanical transmitters of T. gondii oocysts.

The risk of acquiring $T$. gondii infections in adult felids was higher compared to that in juveniles. Only one giant cat (tiger: death after birth due to meconium aspiration), which was 1 day old, was determined to be $T$. gondii antibody- negative. Increasing rates of prevalence of $T$. gondii antibodies in older felids indicated postnatal exposure to $T$. gondii, which was in agreement with the results of previous study (Ramos Silva et al., 2007; Abdou et al., 2013). Gender difference was not a risk factor for toxoplasmosis in the felids examined in this survey.

Taken together, the seroprevalence of $T$. gondii in captive felids from Henan Province was 21.3\% (10/47) in the present study. In Henan Province, the seroprevalence of T. gondii in free-range chickens was $18.9 \%(132 / 700)$ (Feng et al., 2016), 51.6\% in cats (16/31) (Yang et al., 2015), 12.7\% (99/779), and 20.7 (174/840) in domestic sheep (Zhang et al., 2016; Yang et al., 2017), 23.7\% (627/2642) in pig (Wen et al., 2015), and 10.2\% (20/197) in farmreared ostriches (unpublished data). Compared to these reports, the seroprevalence of T. gondii was similar in captive felids from the same location, although only a limited number of samples were examined. The results of the present study were indicative of a widespread T. gondii infection of animals in Henan Province. This also indicated that there is a potential threat of $T$. gondii infection in humans and other animals.

Special economic animal feeding schemes have been developed for the masked palm civet as these have become a huge industry in China, particularly by using its fur, meat, and in producing "Civet coffee." However, masked palm civets carry several pathogens that may zoonosis. Our understanding of $T$. gondii infection status in masked palm civets is limited, which speculate could shed millions of T. gondii oocysts via their feces. No T. gondii DNA was detected in masked palm civet from the Fujian zoo (Chen et al., 2015). Approximately 27.6\% of masked palm civets from farms in Hainan Province were T. gondii seropositive; however, we have no clear information on the composition of their feed (Hou et al., 2016). Farm-reared masked palm civets were all negative for $T$. gondii $(0 / 10)$ in this study. The climate between Henan Province (humid and subtropical) and Hainan Province (tropical) may have contributed to this difference. Furthermore, our results suggest that thoroughly cooked chicken meat, washed fruits and vegetables may prevent toxoplasmosis. More risk assessment of T. gondii should be conducted in farm-reared felids.

In China, zoos are public places where humans spend some leisure time. The oocysts of $T$. gondii that are shed by captive felids may be a risk for tourists and people working in the zoos. In 2010, $13.73 \%$ of the workers in Shenzhen zoos were seropositive for $T$. gondii, thereby rendering it as a high risk population for toxoplasmosis (Xie et al., 2010). The correlation between the risk for infection with $T$. gondii between tourists and captive felids in zoos should thus be explored in future investigation. Toxoplamosis in lions and tigers was first reported in 1989 (Dorny and Fransen, 1989; Ocholi et al., 1989). The seropravalence of captive felids in various zoos in China have been reported, including in that in Shanghai $(84.2 \%, 16 / 19)$ (Zhang et al., 2000), Chengdu (60.9\%, 14/23) (Zhao et al., 2009), 

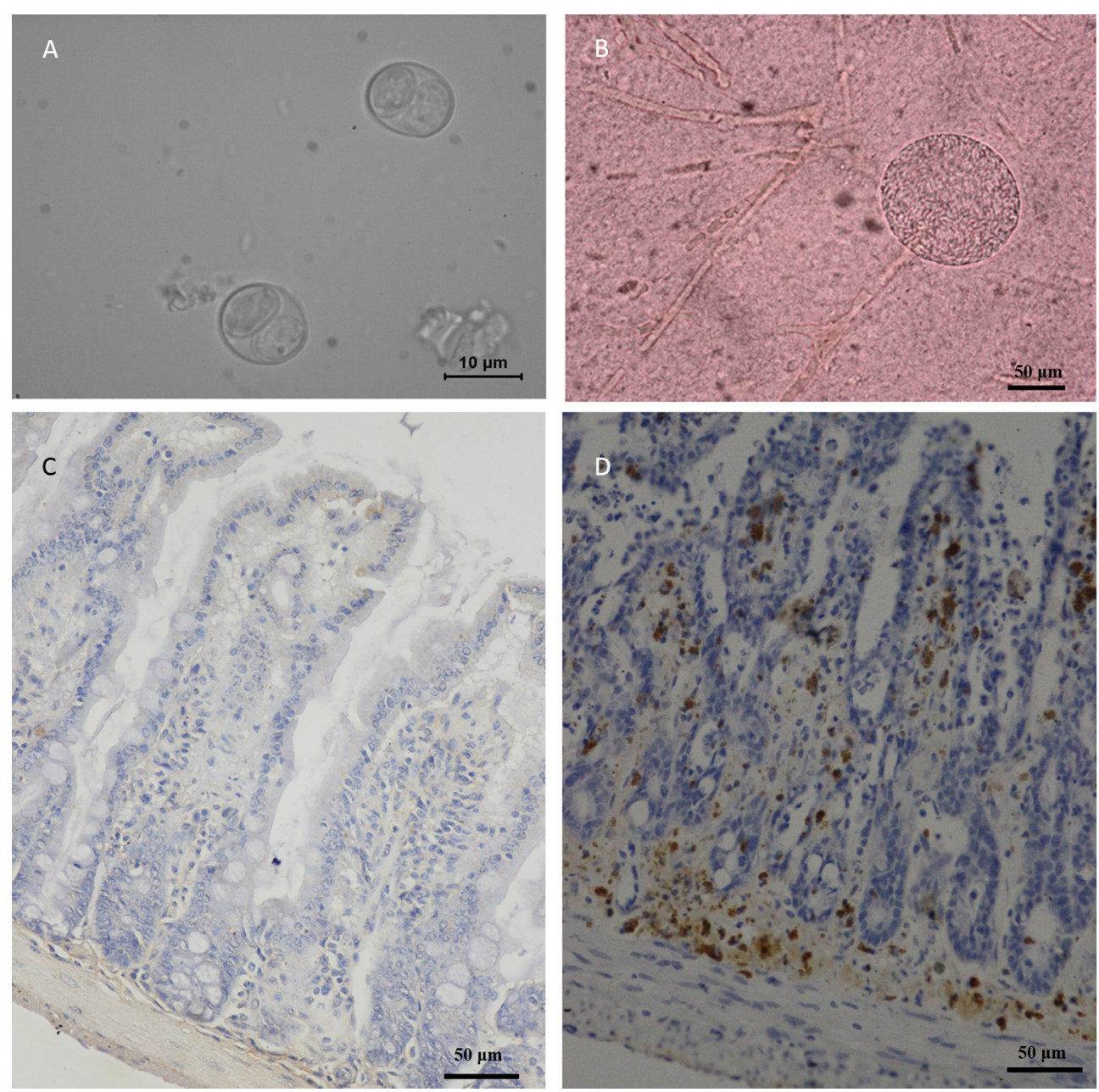

FIGURE 2 | Morphology of TgcatHn4 strain T. gondii and the pathological changes in the ileum of Swiss mice. (A), T. gondii oocysts were detected in cat fecal samples, 6 DPI, unstained; (B), Tissue cysts of T. gondii in mouse brain, 138 DPI, squash, unstained; (C), lleal lesions were not found, mouse, 60 DPI, T. gondii IHC staining; (D), Positive control, ToxoDB\#216, ileum, mouse, $6 \mathrm{~h}$ post-inoculation, T. gondii IHC staining.

Beijing (43.8\%, 7/16) (Zhao et al., 2015), and Fuzhou (40.0\%, 2/5) (Chen et al., 2015). In Henan Province, the T. gondii seropositive rate of felids in tigers and lions $(88.9 \%)$ and had a high titer in MAT (Table 1), which was higher than that in other zoos from the China. The prevalence of $T$. gondii antibodies in zoo felids was $81.4 \%$ (35/43) in Mexico (Alvarado-Esquivel et al., 2013), 36.2\% (51/141) (de Camps et al., 2008), and 59.3\% (35/59) (Spencer et al., 2003) in United States, 15.4\% (21/136) in Thailand (Thiangtum et al., 2006), 75.0\% (6/8) in Portugal (Tidy et al., 2017), 69.6\% (16/23) in Australia(Hill et al., 2008), and 64.9\% (24/37) (Silva et al., 2001b), 54.6\% (472/865) (Silva et al., 2001a), $66.7 \%$ (38/57) (Ullmann et al., 2010) in Brazil. All these higher seropositive rates for $T$. gondii in zoo felids reveal a widespread exposure to $T$. gondii in captive felids from zoos around the world.

One viable $T$. gondii strain was isolated from cat tissues in the present study, followed by a previous report from Chinese cats (Yang et al., 2015), and this strain was designated as TgCatCHn4. Genotyping of these isolates indicated that it was of the ToxoDB genotype \#9 (Chinese 1) by 10 genetic makers. Although T. gondii infection occurs at a low level in the cats from pet hospitals $(7.1 \%)$, prevented measures against toxoplasmosis should continue to be implemented. Efforts in controlling $T$. gondii infections in pet cats, including offering commercial food, inactivation of fecal $T$. gondii oocysts, and monitoring proper hygiene should be recognized. The isolation of viable $T$. gondii is the gold standard for detecting live T. gondii parasites. However, the success in there isolation is influenced by the density of $T$. gondii cysts in the tissues. The heart has been proven as the ideal tissue for the isolation of $T$. gondii compared to the brain or muscle (Dubey et al., 2015). However, the density and distribution of T. gondii cysts in tissues depend on the concentration of initial infected parasites and its virulence. Unsuccessfully isolations may be related to the low density of T. gondii cysts in felids from these samples. Approximately 122 viable $T$. gondii strain have been isolated from animals and 
TABLE 3 | Virulence of the oocyst of TgCatCHn4 T. gondii strain (ToxoDB\#9) on Swiss mice by orally (60 days post-inoculation).

\begin{tabular}{lccc}
\hline $\begin{array}{l}\text { No. of } \\
\text { oocysts fed }\end{array}$ & $\begin{array}{c}\text { No. of infections/No. } \\
\text { of inoculations (\%) }\end{array}$ & $\begin{array}{c}\text { Days of } \\
\text { survival }^{\mathbf{a}}\end{array}$ & Brain cysts \\
\hline $10^{5}$ & $5 / 5(100 \%)$ & $\geq 60 / 5$ & Not found \\
$10^{4}$ & $5 / 5(100 \%)$ & $\geq 60 / 5$ & Not found \\
$10^{3}$ & $5 / 5(100 \%)$ & $\geq 60 / 5$ & Not found \\
$10^{2}$ & $3 / 5(60 \%)$ & $\geq 60 / 5$ & Not found \\
$10^{1}$ & $2 / 5(40 \%)$ & $\geq 60 / 5$ & Not found \\
1 & $1 / 5(20 \%)$ & $\geq 60 / 5$ & Not found \\
$<1$ & 0 & $\geq 60 / 5$ & Not found \\
Blank control & 0 & $\geq 60 / 5$ & Not found \\
\hline
\end{tabular}

${ }^{a}$ Mouse survival days/Number of surviving mice.

humans in China. Among these, 85 T. gondii isolates were from cats, and 73 (85.9\%) T. gondii isolates were genotyped as ToxoDB\#9 (Dubey et al., 2007; Yang et al., 2015, 2017; Wang et al., 2016). Combined with our results, ToxoDB\#9 is the predominant strain in China.

The virulence of the isolated strain TgCatCHn 4 was evaluated via oral administration in outbred Swiss mice. The T. gondii oocysts were collected from the feces of cat. The first batch oocysts were detected on the sixth day post feeding and significantly reduced by the 11th day, which coincident with the findings of a previous report (Dubey and Prowell, 2013). The oocysts presented extremely weak pathogenicity and a lower cyst forming rate (Table 2). Furthermore, this strain showed favorable adaptive capacity in the intestines of the host, and the intestine lesions were not found at 60 DPI (Figure 2C). A growing number of research studies have shown that the same T. gondii genotype may exhibit different virulence and

\section{REFERENCES}

Abdou, N. E., Al-Batel, M. K., El-Azazy, O. M., Sami, A. M., and Majeed, Q. A. (2013). Enteric protozoan parasites in stray cats in Kuwait with special references to toxoplasmosis and risk factors affecting its occurrence. J. Egypt. Soc. Parasitol. 43, 303-314. doi: 10.12816/0006387

Alvarado-Esquivel, C., Gayosso-Dominguez, E. A., Villena, I., and Dubey, J. P. (2013). Seroprevalence of Toxoplasma gondii infection in captive mammals in three zoos in Mexico City, Mexico. J. Zoo Wildl. Med. 44, 803-806. doi: 10.1638/2013-0032.1

Chen, R., Lin, X., Hu, L., Chen, X., Tang, Y., Zhang, J., et al. (2015). Genetic characterization of Toxoplasma gondii from zoo wildlife and pet birds in Fujian, China. Iran. J. Parasitol. 10, 663-668.

Chen, Z. W., Gao, J. M., Huo, X. X., Wang, L., Yu, L., Halm-Lai, F., et al. (2011). Genotyping of Toxoplasma gondii isolates from cats in different geographic regions of China. Vet. Parasitol. 183, 166-170. doi: 10.1016/j.vetpar.2011.06.013

Cheng, W., Liu, F., Li, M., Hu, X., Chen, H., Pappoe, F., et al. (2015). Variation detection based on next-generation sequencing of type Chinese 1 strains of Toxoplasma gondii with different virulence from China. BMC Genomics 16:888. doi: 10.1186/s12864-015-2106-Z

de Camps, S., Dubey, J. P., and Saville, W. J. A. (2008). Seroepidemiology of Toxoplasma gondii in zoo animals in selected zoos in the midwestern United States. J. Parasitol. 94, 648-653. doi: 10.1645/GE-1453R.1

Dorny, P., and Fransen, J. (1989). Toxoplasmosis in a Siberian tiger (Panthera tigris altaica). Vet. Rec. 125, 647 pathogenicity in the same animals. Cheng et al. (2015) reported that the ToxoDB\#9 genotype in different stains has different virulence and pathogenicity rates in mice. Two ToxoDB\#9 strains from sheep differences in virulence, pathogenicity, and encystation among mice, and CV-1 cells (Yang et al., 2017). Recently, Verma et al. (2017) reported that the same genotype of T. gondii in bobcats shared different polymorphic genes of GRA6 and GRA7. The resuslts indicated that 10 genetic makers may be not enough for identify the genotype of $T$. gondii, sequence analysis may be more accurate. Further, no evaluation standard for virulence in $T$. gondii has been established, which could facilitate in understanding the pathogenic relationships between T. gondii and its hosts.

In conclusion, the high prevalence of $T$. gondii infection in captive felids should be examined in more detail. Preventive measures against oocysts contamination of the environment must be further evaluated, including the use of pre-frozen meat, cleaned fruits and vegetables, monitoring birds and rodents, inactiving oocysts from feces, and proper hygiene.

\section{AUTHOR CONTRIBUTIONS}

YY performed the data analysis and wrote the manuscript. YF performed the laboratory tests. YL, HD, TL, and YJ helped in collecting samples. XZ participated in the RFLP analysis. LZ helped in the revising of the manuscript.

\section{FUNDING}

This research project was financed by the National Key Research and Development Program of China (2016YFD0500707) and China Postdoctoral Science Foundation (2016M600577).

Dubey, J. P. (2010). Toxoplasmosis of Animals and Humans, 2nd Edn. Boca Raton, FL: CRC Press. 1-313.

Dubey, J. P., and Desmonts, G. (1987). Serological responses of equids fed Toxoplasma gondii oocysts. Equine Vet. J. 19, 337-339. doi: 10.1111/j.2042-3306.1987.tb01426.x

Dubey, J. P., Ferreira, L. R., Martins, J., and McLeod, R. (2012). Oral oocystinduced mouse model of toxoplasmosis: effect of infection with Toxoplasma gondii strains of different genotypes, dose, and mouse strains (transgenic, out-bred, in-bred) on pathogenesis and mortality. Parasitology 139, 1-13. doi: 10.1017/s0031182011001673

Dubey, J. P., Lehmann, T., Lautner, F., Kwok, O. C., and Gamble, H. R. (2015). Toxoplasmosis in sentinel chickens (Gallus domesticus) in New England farms: seroconversion, distribution of tissue cysts in brain, heart, and skeletal muscle by bioassay in mice and cats. Vet. Parasitol. 214, 55-58. doi: 10.1016/j.vetpar.2015.09.004

Dubey, J. P., and Prowell, M. (2013). Ante-mortem diagnosis, diarrhea, oocyst shedding, treatment, isolation, and genetic typing of Toxoplasma gondii associated with clinical toxoplasmosis in a naturally infected cat. J. Parasitol. 99, 158-160. doi: 10.1645/GE-3257.1

Dubey, J. P., Zhu, X. Q., Sundar, N., Zhang, H., Kwok, O. C., and Su, C. (2007). Genetic and biologic characterization of Toxoplasma gondii isolates of cats from China. Vet. Parasitol. 145, 352-356. doi: 10.1016/j.vetpar.2006.12.016

Feng, Y., Lu, Y., Wang, Y., Liu, J., Zhang, L., and Yang, Y. (2016). Toxoplasma gondii and Neospora caninum in free-range chickens in Henan province of China. Biomed Res. Int. 2016:8290536. doi: 10.1155/2016/8290536 
Hide, G. (2016). Role of vertical transmission of Toxoplasma gondii in prevalence of infection. Expert Rev. Anti Infect. Ther. 14, 335-344. doi: 10.1586/14787210.2016.1146131

Hill, N. J., Dubey, J. P., Vogelnest, L., Power, M. L., and Deane, E. M. (2008). Do free-ranging common brushtail possums (Trichosurus vulpecula) play a role in the transmission of Toxoplasma gondii within a zoo environment? Vet. Parasitol. 152, 202-209. doi: 10.1016/j.vetpar.2008.01.002

Hou, G. Y., Zhao, J. M., Zhou, H. L., and Rong, G. (2016). Seroprevalence and genetic characterization of Toxoplasma gondii in masked palm civet (Paguma larvata) in Hainan province, tropical China. Acta Trop. 162, 103-106. doi: 10.1016/j.actatropica.2016.06.011

Johnson, W. E., Eizirik, E., Pecon-Slattery, J., Murphy, W. J., Antunes, A., Teeling, E., et al. (2006). The late Miocene radiation of modern Felidae: a genetic assessment. Science 311, 73-77. doi: 10.1126/science.1122277

Li, Y. N., Nie, X., Peng, Q. Y., Mu, X. Q., Zhang, M., Tian, M. Y., et al. (2015). Seroprevalence and genotype of Toxoplasma gondii in pigs, dogs and cats from Guizhou province, Southwest China. Parasit. Vectors 8, 214. doi: 10.1186/s13071-015-0809-2

Miller, M. A., Grigg, M. E., Kreuder, C., James, E. R., Melli, A. C., Crosbie, P. R., et al. (2004). An unusual genotype of Toxoplasma gondii is common in California sea otters (Enhydra lutris nereis) and is a cause of mortality. Int. J. Parasitol. 34, 275-284. doi: 10.1016/j.ijpara.2003.12.008

Ocholi, R. A., Kalejaiye, J. O., and Okewole, P. A. (1989). Acute disseminated toxoplasmosis in two captive lions (Panthera leo) in Nigeria. Vet. Rec. 124, 515-516. doi: 10.1136/vr.124.19.515

Qian, W., Wang, H., Su, C., Shan, D., Cui, X., Yang, N., et al. (2012). Isolation and characterization of Toxoplasma gondii strains from stray cats revealed a single genotype in Beijing, China. Vet. Parasitol. 187, 408-413. doi: 10.1016/j.vetpar.2012.01.026

Ramos Silva, J. C., Marvulo, M. F., Dias, R. A., Ferreira, F., Amaku, M., Adania, C. H., et al. (2007). Risk factors associated with sero-positivity to Toxoplasma gondii in captive neotropical felids from Brazil. Prev. Vet. Med. 78, 286-295. doi: 10.1016/j.prevetmed.2006.10.013

Silva, J. C., Ogassawara, S., Adania, C. H., Ferreira, F., Gennari, S. M., Dubey, J. P., et al. (2001a). Seroprevalence of Toxoplasma gondii in captive neotropical felids from Brazil. Vet. Parasitol. 102, 217-224. doi: 10.1016/S0304-4017(01) 00523-4

Silva, J. C., Ogassawara, S., Marvulo, M. F., Ferreira-Neto, J. S., and Dubey, J. P. (2001b). Toxoplasma gondii antibodies in exotic wild felids from Brazilian zoos. J. Zoo Wildl. Med. 32, 349-351. doi: 10.1638/10427260(2001)032[0349:TGAIEW2.0.CO;2]

Spencer, J. A., Higginbotham, M. J., and Blagburn, B. L. (2003). Seroprevalence of Neospora caninum and Toxoplasma gondii in captive and free-ranging nondomestic felids in the United States. J. Zoo Wildl. Med. 34, 246-249. doi: 10.1638/02-046

Su, C., Shwab, E. K., Zhou, P., Zhu, X. Q., and Dubey, J. P. (2010). Moving towards an integrated approach to molecular detection and identification of Toxoplasma gondii. Parasitology 137, 1-11. doi: 10.1017/s00311820099 91065

Thiangtum, K., Nimsuphun, B., Pinyopanuwat, N., Chimnoi, W., Tunwattana, W., Tongthainan, D., et al. (2006). Seroprevalence of Toxoplasma gondii in captive felids in Thailand. Vet. Parasitol. 136, 351-355. doi: 10.1016/j.vetpar.2005.12.009

Tidy, A., Fangueiro, S., Dubey, J. P., Cardoso, L., and Lopes, A. P. (2017). Seroepidemiology and risk assessment of Toxoplasma gondii infection in captive wild birds and mammals in two zoos in the North of Portugal. Vet. Parasitol. 235, 47-52. doi: 10.1016/j.vetpar.2017.01.004

Ullmann, L. S., da Silva, R. C., de Moraes, W., Cubas, Z. S., dos Santos, L. C., Hoffmann, J. L., et al. (2010). Serological survey of Toxoplasma gondii in captive Neotropical felids from Southern Brazil. Vet. Parasitol. 172, 144-146. doi: 10.1016/j.vetpar.2010.04.013
Vanwormer, E., Carpenter, T. E., Singh, P., Shapiro, K., Wallender, W. W., Conrad, P. A., et al. (2016). Coastal development and precipitation drive pathogen flow from land to sea: evidence from a Toxoplasma gondii and felid host system. Sci. Rep. 6:29252. doi: 10.1038/srep 29252

Verma, S. K., Sweeny, A. R., Lovallo, M. J., Calero-Bernal, R., Kwok, O. C., Jiang, T., et al. (2017). Seroprevalence, isolation and co-infection of multiple Toxoplasma gondii strains in individual bobcats (Lynx rufus) from Mississippi, U. S. A. Int. J. Parasitol. 47, 297-303. doi: 10.1016/j.ijpara.2016. 12.007

Wang, D., Liu, Y., Jiang, T., Zhang, G., Yuan, G., He, J., et al. (2016). Seroprevalence and genotypes of Toxoplasma gondii isolated from pigs intended for human consumption in Liaoning province, northeastern China. Parasit. Vectors 9, 248. doi: 10.1186/s13071-016-1525-2

Wang, L., Chen, H., Liu, D., Huo, X., Gao, J., Song, X., et al. (2013). Genotypes and mouse virulence of Toxoplasma gondii isolates from animals and humans in China. PLoS ONE 8:e53483. doi: 10.1371/journal.pone.0053483

Wen, Q. N., Guo, Y. H., Yang, J. F., Shen, H., and Du, Y. C. (2015). Investigation on epidemiology of toxoplasmosis in pig from Henan province. Chin. J. Vet. Med. $51,44-45$.

Xie, G. P., Geng, Y. J., Wu, Y., Zhang, R. L., Li, Q., Huang, D. N., et al. (2010). Serological survey of Toxplasma gondii infection in wild animal breeders in Shenzhen. Chin. Tropical Med. 10, 426-427. doi: 10.13604/j.cnki.46-1064/r.2010.04.035

Yang, Y., Ying, Y., Verma, S. K., Cassinelli, A. B., Kwok, O. C., Liang, H., et al. (2015). Isolation and genetic characterization of viable Toxoplasma gondii from tissues and feces of cats from the central region of China. Vet. Parasitol. 211, 283-288. doi: 10.1016/j.vetpar.2015.05.006

Yang, Y., Feng,Y., Yao, Q., Wang, Y., Lu, Y., Liang, H., et al. (2017). Seroprevalence, isolation, genotyping, and pathogenicity of Toxoplasma gondii Strains from sheep in China. Front. Microbiol. 8:136. doi: 10.3389/fmicb.2017.00136

Zhang, N., Wang, S., Wang, D., Li, C., Zhang, Z., Yao, Z., et al. (2016). Seroprevalence of Toxoplasma gondii infection and risk factors in domestic sheep in Henan province, central China. Parasite 23, 53. doi: 10.1051/parasite/2016064

Zhang, S. Y., Wei, M. X., Zhou, Z. Y., Yu, J. Y., and Shi, X. Q. (2000). Prevalence of antibodies to Toxoplasma gondii in the sera of rare wildlife in the shanghai zoological garden, people's republic of China. Parasitol. Int. 49, 171-174. doi: 10.1016/S1383-5769(00)00041-6

Zhao, B., Wang, Q., Yan, H. J., Yang, G. Y., Niu, L. L., Deng, J. B., et al. (2009). Investigation on protozoa and Dirofilaria immitis infections for wild animals in Chengdu Zoo. Chin. Vet. Sci. 39, 277-282. doi: 10.16656/j.issn.1673-4696.2009.03.017

Zhao, J., Cang, Y. J., and Wang, X. (2015). Investigation of Toxoplasma gondii infection in feral cats and wild animals in Beijing zoo. Chin. J. Wildl. 36, 270-274. doi: 10.3969/j.issn.1000-0127.2015.03.004

Zhou, P., Zhang, H., Lin, R. Q., Zhang, D. L., Song, H. Q., Su, C., et al. (2009). Genetic characterization of Toxoplasma gondii isolates from China. Parasitol. Int. 58, 193-195. doi: 10.1016/j.parint.2009.01.006

Conflict of Interest Statement: The authors declare that the research was conducted in the absence of any commercial or financial relationships that could be construed as a potential conflict of interest.

Copyright (๑) 2017 Yang, Feng, Lu, Dong, Li, Jiang, Zhu and Zhang. This is an open-access article distributed under the terms of the Creative Commons Attribution License (CC BY). The use, distribution or reproduction in other forums is permitted, provided the original author(s) or licensor are credited and that the original publication in this journal is cited, in accordance with accepted academic practice. No use, distribution or reproduction is permitted which does not comply with these terms. 